\title{
Reducing Hospital Stays with Community Wide Programs
}

\author{
Ronald Lagoe*, Gretchen Lagoe \\ Hospital Executive Council, Syracuse, NY, USA \\ Email: *Hospexcl@cnymail.com
}

How to cite this paper: Lagoe, R. and Lagoe, G. (2020) Reducing Hospital Stays with Community wide Programs. Case Reports in Clinical Medicine, 9, 67-73.

https://doi.org/10.4236/crcm.2020.93011

Received: February 11, 2020

Accepted: March 14, 2020

Published: March 17, 2020

Copyright $\odot 2020$ by author(s) and Scientific Research Publishing Inc. This work is licensed under the Creative Commons Attribution International License (CC BY 4.0).

http://creativecommons.org/licenses/by/4.0/

\begin{abstract}
This study provided an update concerning programs for reduction of inpatient lengths of stay in the three Syracuse hospitals. The study included evaluation of the impact of these programs by severity of illness. The Difficult to Place program involved the identification of patients with extended stays in the hospitals because of the need for long term care services in the community. A community wide list of Difficult to Place patients was distributed by the Hospital Executive Council each week. In addition, the Syracuse hospitals and the Hospital Executive Council implemented the Subacute and Complex Care Programs for patients with extended stays. These inpatients included those who required expensive medication or patients with infectious diseases and offsite transportation. The study data indicated that Difficult to Place patients in the combined Syracuse hospitals amounted to $20.4-20.5$ percent of new admissions to nursing homes between 2017 and 2019. The data also demonstrated that the number of Subacute and Complex Care patients for the combined hospitals amounted to 5.7 to 6.6 percent of the Difficult to Place populations. The study data indicated that adult medicine lengths of stay declined by 0.10 patient days, from 4.91 to 4.81 days between 2017 and 2019, a reduction of 12,622 patient days or an average daily census of 34.6. The study data indicated that adult surgery lengths of stay declined by 0.22 patient days, from 5.55 to 5.33 days between 2017 and 2019, a reduction of 8681 patient days, or an average daily census of 23.8 .
\end{abstract}

\section{Keywords}

Hospitals, Nursing Homes, Long Term Care

\section{Introduction}

Historically, the need for improved efficiency has been a major challenge for 
health care providers in the United States. Health care expenses have increased at a higher rate than the cost of living for many years [1].

Much of this challenge has been related to inpatient hospitals. As the most expensive component of the health care system, acute care providers have frequently struggled to maintain efficient utilization [2].

To some extent, hospitals are challenged to maintain efficiency because of costs that are out of their control. These include pharmaceutical and labor costs that account for a large part of their expenses.

Hospitals are also challenged to maintain efficiency by controlling inpatient utilization, especially lengths of stay. As providers of care for patients with the highest severity of illness, hospitals are frequently responsible for the expenses of patients with the highest cost of care. These patients can remain on acute care for extended periods consuming large amounts of resources [3] [4].

For hospitals, the challenges of controlling lengths of stay are also generated by the need to discharge patients to post acute services. Many of these patients require extended care after discharge in nursing homes that are not within the control of acute care providers [5] [6].

Among these organizations are long term care providers including nursing homes and home health agencies. These long term care organizations do not have the financial incentives to admit patients who require complicated post hospital care [7].

In these circumstances, many hospitals have been left to develop their own programs for discharging some patients, including those who require complex care. These programs have needed to address the care needs of these patients at the community level, as well as legal and administrative considerations [8] [9] [10].

The objective of this study was to provide an update concerning community wide programs for length of stay reduction developed by the hospitals and nursing homes of Syracuse, New York. These programs focused on efforts by these providers to limit hospital stays by moving patient days from acute care to long term care settings.

\section{Population}

This study evaluated programs for improving efficiency in the hospitals of Syracuse, New York. These providers include Crouse Hospital (18,862 discharges excluding well newborns, 2019); St. Joseph's Hospital Health Center, (25,249 discharges, 2019); and Upstate University Hospital, (32,877 discharges, 2019).

The Syracuse hospitals provide primary and secondary acute care to a service area with a population of approximately 600,000 . They also provide tertiary services to the Central New York Health Service Area with a population of approximately $1,400,000$.

Historically, the Syracuse hospitals have worked cooperatively to improve the efficiency of acute care in their service area. These efforts have included pro- 
grams that reduce inpatient stays, limit inpatient admissions, and improve outcomes.

Some of these programs have been implemented by individual hospitals. A number of them have also been developed for all three of the hospitals through the Hospital Executive Council, a collaborative planning organization [10].

\section{Method}

This study provided an update concerning programs for reduction of inpatient lengths of stay in the three Syracuse hospitals. It focused on mechanisms developed and implemented through the Hospital Executive Council.

The study included evaluation of the impact of these programs by severity of illness. It was based on the recognition that the largest opportunities for reduction of excess hospital stays in the Syracuse hospitals involved acute care patients with high severity of illness. For purposes of the study, severity of illness was defined by the All Patients Refined Diagnosis Related Group System developed by $3 \mathrm{M}^{\mathrm{TM}}$ Health Information Systems.

The most basic of these initiatives was the Difficult to Place Program. This effort involved the identification of patients with extended stays and the potential for extended stays in the hospitals because of the need for post discharge services in the community. Within this program, patients who were Difficult to Place in nursing homes and home health agencies were identified by each hospital. A community wide list of these patients with names encrypted was distributed by the Hospital Executive Council each week. In addition, summaries of numbers of these patients by hospital and nursing home were distributed by the Hospital Executive Council each month.

In addition to the Difficult to Place Program, the Syracuse hospitals and the Hospital Executive Council developed and implemented the Subacute and Complex Care Programs for patients with extended stays who were most difficult to discharge. These inpatients included those who required expensive medications for infectious diseases and other diagnoses, offsite transportation, and wound care.

For the Subacute and Complex Care Programs, the hospitals provided Program Development Grants through the Hospital Executive Council. These grants were provided through a community wide pool of funding administered by the Hospital Executive Council. The grants were provided at fixed amounts so they did not fund individual patients.

The first component of the study identified numbers of Difficult to Place, Subacute, and Complex Care patients in these programs between 2017 and 2019. It also included utilization of the specific Subacute and Complex Care Programs. Differences in utilization of these programs during the three year period were compared.

The second component of the study identified lengths of stay by severity of illness for adult medicine and adult surgery patients in the Syracuse hospitals 
during the three year period. It included evaluation of changes in lengths of stay and related utilization.

The study was limited to evaluation of the use of Difficult to Place, Subacute, and Complex Care Programs in the Syracuse hospitals between 2017 and 2019. This information provided an update concerning the most recent experience with these programs.

\section{Results}

The first component of the study identified numbers of patients for each of the Syracuse hospitals in the Difficult to Place, Subacute, and Complex Care Programs. Relevant data are summarized in Table 1.

The data in Table 1 indicated that total new admissions to nursing homes for the combined Syracuse hospitals ranged from 7290 to 7794 during the period of the study. The 6.9 percent increase in these data was probably related to the aging of local populations and increased utilization of the Programs. In 2019, the total new admissions to nursing homes accounted for 13.2 percent of the adult medicine and adult surgery populations of the combined hospitals.

The study data also indicated the numbers of Difficult to Place patients in the combined hospitals ranged from 1485 to 1594 between 2017 and 2019. This level amounted to 20.4 - 20.5 percent of new admissions to nursing homes. This information indicated that the rates at which new admissions to nursing homes were identified as Difficult to Place were relatively stable.

The data in Table 1 also indicated that the numbers of Subacute and Complex Care patients for the combined hospitals ranged from 84 to 100 during the three year period. These levels amounted to 5.7 to 6.6 percent of the Difficult to Place populations. These data suggested that Difficult to Place patients were being assigned to these programs at conservative rates.

Within the Subacute and Complex Care Programs, the Complex Care Programs that supported patient care involving intravenous therapy and extended wound care accounted for 52.7 percent of the total. The intravenous therapy programs included medications such as meripenem, oxacillin, and daptomycin.

Table 1. Inpatient long term care utilization, Syracuse Hospitals, 2017-2019.

\begin{tabular}{|c|c|c|c|c|c|c|c|c|c|}
\hline & \multicolumn{3}{|c|}{$\begin{array}{l}\text { New Admissions to } \\
\text { Nursing Homes }\end{array}$} & \multicolumn{3}{|c|}{$\begin{array}{l}\text { Number of Difficult } \\
\text { to Place Patients }\end{array}$} & \multicolumn{3}{|c|}{$\begin{array}{c}\text { Number of } \\
\text { Subacute/Complex } \\
\text { Care Patients }\end{array}$} \\
\hline & 2017 & 2018 & 2019 & 2017 & 2018 & 2019 & 2017 & 2018 & 2019 \\
\hline Crouse Hospital & 1830 & 2112 & 1818 & 290 & 271 & 364 & 17 & 25 & 15 \\
\hline $\begin{array}{l}\text { St. Joseph's Hospital Health } \\
\text { Center }\end{array}$ & 2261 & 2407 & 2406 & 658 & 692 & 637 & 54 & 48 & 51 \\
\hline $\begin{array}{l}\text { Upstate University Hospital } \\
\text { SUNY UMU }\end{array}$ & 3199 & 3144 & 3570 & 537 & 542 & 593 & 13 & 27 & 25 \\
\hline Total & 7290 & 7663 & 7794 & 1485 & 1505 & 1594 & 84 & 100 & 91 \\
\hline
\end{tabular}

Source: Hospital Executive Council data. 
For these patients, the programs moved the location of care for the three to six weeks of the stay from hospitals to long term care facilities. The remaining 47.3 percent was generated by the Patient Transportation Program, mainly for dialysis patients.

The data indicated that, among the hospitals, St. Joseph's Hospital Health Center had the highest utilization for the programs. The total number of patients for that hospital accounted for 40.0 - 43.6 percent of the community wide total of Difficult to Place patients and 48.0 - 64.3 percent of the total of Subacute and Complex Care patients.

The second component of the study suggested the impact of the Difficult to Place Program and the Subacute and Complex Care Programs on lengths of stay in the Syracuse hospitals. Relevant data are summarized in Table 2.

This information demonstrated that the mean adult medicine length of stay for the combined Syracuse hospitals declined by 0.10 patient days, from 4.91 to 4.81, between January and December 2017-2019. When multiplied by the number of discharges in the combined hospitals, this resulted in a reduction of 12,622 patient days or an average daily census of 34.6.

The study data indicated that most of this reduction was generated by St. Joseph's Hospital Health Center, where the mean length of stay declined by 0.27 patient days, from 4.52 to 4.25 days or 10,332 days per year. The mean adult medicine length of stay declined by 0.10 days at Upstate University Hospital and increased by 0.19 days at Crouse Hospital.

The information in Table 2 also demonstrated that the mean adult surgery length of stay declined by 0.22 patient days, from 5.55 to 5.33 days, between

Table 2. Inpatient mean lengths of stay, by severity of illness, Syracuse Hospitals, 2017-2019.

\begin{tabular}{cccccc}
\hline & Minor & Moderate & Major & Extreme & Total \\
\hline Adult Medicine & & & & & \\
Jan - Dec 2017 & 2.52 & 3.52 & 5.76 & 10.76 & 4.91 \\
Jan - Dec 2018 & 2.55 & 3.38 & 5.63 & 10.27 & 4.85 \\
Jan - Dec 2019 & 2.58 & 3.50 & 5.30 & 9.37 & 4.81 \\
Length of Stay Difference (2017-2019) & 0.06 & -0.02 & -0.46 & -1.39 & -0.10 \\
Patient Days Difference (2017-2019) & 308.29 & -227.55 & -5722.24 & -6980.58 & $-12,622.08$ \\
Adult Surgery & & & & & \\
Jan - Dec 2017 & & & & & \\
Jan - Dec 2018 & 2.51 & 3.99 & 8.71 & 19.83 & 5.55 \\
Jan - Dec 2019 & 2.35 & 3.83 & 8.66 & 18.85 & 5.36 \\
Patient Days Difference (2017-2019) & -1964.76 & -1864.46 & -1002.74 & -3849.46 & -8681.42 \\
\hline Length of Stay Difference (2017-2019) & -0.22 & -0.21 & -0.25 & -1.81 & -0.22 \\
\hline
\end{tabular}

Adult medicine data exclude Diagnosis Related Groups concerning surgery, obstetrics, psychiatry, alcohol/substance abuse treatment, rehabilitation, and all patients aged 0 - 17 years. Adult surgery data exclude Diagnosis Related Groups concerning medicine, obstetrics, psychiatry, alcohol/substance abuse treatment, and all patients aged 0 - 17 years. Source: Hospital Executive Council. 
January and December 2017-2019. When multiplied by the numbers of discharges in the combined hospitals, this resulted in a reduction of 8681 patient days or an average daily census of 23.8

The study data indicated that a reduction of 0.34 days, or 3631 patient days occurred in the mean length of stay for St. Joseph's Hospital Health Center, 0.34 days or 3579 patient days for Upstate University Hospital, and 0.13 days or 1470 total days for Crouse Hospital.

\section{Discussion}

The need for greater efficiency will continue to challenge health care providers, especially hospitals. Reduction of hospital lengths of stay is an important part of addressing this need at the community level. The study provided an update on this process in the hospitals of Syracuse, New York.

The study demonstrated how acute care and long term care providers could plan and implement programs to improve hospital efficiency and outcomes at the community level. This process involved moving three to six weeks of extended hospital stays to nursing homes. The planning and evaluation of this process were coordinated through the Hospital Executive Council.

This study indicated that, in these hospitals, inpatient stays could be reduced by focusing on specific populations. These included Difficult to Place patients in nursing homes, who comprised approximately 20 percent of admissions to these facilities. They also included patients requiring complex care such as intravenous antibiotic therapy. They comprised 5 - 7 percent of Difficult to Place patients.

The study suggested that programs addressing these populations in hospitals could reduce inpatient days by shifting 3 - 6 weeks of extended stays to long term care facilities. These programs improved the efficiency and the outcomes of care.

In Syracuse, the Difficult to Place, Subacute, and Complex Care Programs that have been addressing these needs were developed by all of the acute hospitals and the larger nursing homes. This community wide process provided greater capacity and flexibility than the use of individual hospital to nursing home partnerships would have.

The study data suggested that utilization of the Difficult to Place, Subacute, and Complex Care Programs was associated with length of stay reduction in the Syracuse Hospitals. Between 2017 and 2019, this reduction amounted to 21,000 annual inpatient days or an average daily census of 58.4 patients. The reductions in stays were largest at the hospital with the highest utilization of the programs.

Based on utilization data from 2017 to 2019, the annual costs of implementing these programs was approximately $\$ 332,000$. Most of these costs involved program development expenses for medications that the hospitals would have incurred anyway if the patients remained for extended periods. Based on the expense of $\$ 600$ per hospital patient day at the end of the stay, the annual savings in patient days through the programs during the three year period was approx- 
imately 21,000 , or approximately $\$ 12,600,000$.

As the need for increased efficiency of health care providers continues, efforts to develop programs at the community level should continue. Length of stay reduction should be an important part of these efforts.

\section{Conflicts of Interest}

The authors declare no conflicts of interest regarding the publication of this paper.

\section{References}

[1] Dentzler, S. (2011) Urgent Measures for an Old Problem. Health Affairs, 30, 1626. https://doi.org/10.1377/hlthaff.2011.0961

[2] Meyer, H. (2018) The Price Problem. Modern Healthcare, 48, 20-24.

[3] Cushing, W.T. (2004) Extra Hospital Days Can Cost You Plenty. Medical Economics, 81, 83 .

[4] Friedman, B., De La Mare, J., Andrews, R. and McKenzie, D.H. (2002) Practical Opportunities for Estimating the Costs of Hospital Stays. Journal of Health Care Finance, 291, 1-12.

[5] Hong, C.S., Siegel, A.L. and Ferris, T.G. (2014) Caring for High Need, High Cost Patients: What Makes a Successful Case Management Program? Commonwealth Fund, New York. https://doi.org/10.15868/socialsector.25007

[6] Anderson, G. and Knickman, J.R. (2001) Changing the Chronic Care System to Meet People's Needs. Health Affairs, 20, 146-160. https://doi.org/10.1377/hlthaff.20.6.146

[7] Oriol, W. (1985) The Complex Cube of Long Term Care. American Health Planning Association, Washington DC.

[8] Capitman, J., Haskins, B. and Bernstein, J. (1986) Case Management: Approaches to Community Oriented Long Term Care Demonstrations. Gerontologist, 26, 398-404. https://doi.org/10.1093/geront/26.4.398

[9] Pawlson, L.G. (1994) Chronic Illness: Implications for a New Paradigm of Health Care. Journal of Quality Improvement, 20, 33-39. https://doi.org/10.1016/S1070-3241(16)30051-7

[10] Lagoe, R., Pasinski, T., Kronenberg, P., Quinn, T. and Schaengold, P. (2006) Linking Health Services at the Community Level. Canada Healthcare Quarterly, 9, 60-65. https://doi.org/10.12927/hcq..18229 